\title{
Obesity and Mechanical Thrombectomy
}

David R. Hallan ${ }^{1}$

1. Neurosurgery, Penn State Health Milton S. Hershey Medical Center, Hershey, USA

Corresponding author: David R. Hallan, david_hallan@yahoo.com

\section{Abstract \\ Background}

Obesity has been shown to have a positive mortality benefit in patients undergoing percutaneous coronary intervention, dialysis, those with rheumatoid arthritis, chronic obstructive pulmonary disease, and various wasting diseases. Studies for this mortality benefit in ischemic stroke patients are conflicting, and it has not been well studied in mechanical thrombectomy patients. We sought to determine the impact of obesity on outcomes of mechanical thrombectomy patients.

\section{Methodology}

We used a large global health research network to gather clinical data extracted from the electronic medical records of ischemic stroke patients who underwent mechanical thrombectomy, and then stratified these patients into obese and non-obese cohorts. The primary endpoint was mortality.

\section{Results}

After propensity score matching, obese patients who underwent mechanical thrombectomy had decreased mortality $(p=0.0033$, odds ratio $=0.81,95 \%$ confidence interval $=0.704,0.932)$ compared to non-obese patients. No statistically significant difference was shown between these two cohorts for the outcomes of ventilator dependence, hemicraniectomy, or post-procedure intracerebral hemorrhage.

\section{Conclusion}

Despite increasing risk of ischemic stroke, obese patients who undergo mechanical thrombectomy have decreased mortality rates compared to their non-obese counterparts.

Categories: Neurosurgery

Keywords: neurosurgery, stroke, thrombectomy, obesity, outcomes, mortality, hemorrhagic conversion, trinetx, bmi, cerebrovascular

Received 01/02/2021 Review began 01/07/2021 Review ended 01/11/2021 Published 01/13/2021

๑) Copyright 2021 Hallan. This is an open access article distributed under the terms of the Creative Commons Attribution License CC-BY 4.0., which permits unrestricted use, distribution, and reproduction in any medium, provided the original author and source are credited.

\section{Introduction}

Obesity increases the risk of stroke [1-4]. Risk increases roughly $6 \%$ with increase in body mass index (BMI) [4]. Despite this, obesity has been shown to have a positive mortality benefit in stroke patients [4-14]; however, not all studies agree [15,16]. A recent study examined mortality as an outcome for ischemic stroke patients undergoing mechanical thrombectomy. The study found that higher BMI is associated with decreased intracerebral hemorrhage post-procedure, and that BMI positively correlates with nonhemorrhagic inpatient mortality [3]. We sought to support or refute this claim using a multi-institutional database.

\section{Materials And Methods}

The TriNetX research database was retrospectively queried to evaluate all patients with a diagnosis of ischemic stroke who underwent mechanical thrombectomy. The patients were then divided into cohorts of obese and overweight versus non-obese and non-overweight patients according to the International Classification of Diseases, Tenth Revision code E66. Analysis was performed using unmatched and propensity score-matched cohorts using known stroke risk factors. The primary endpoint was mortality. The secondary endpoints included ventilator dependence, hemicraniectomy, and intracerebral hemorrhage. Hazard ratios were calculated using R Studio's survival package v3.2-3 and were validated comparing the output to that of SAS version 9.4. Chi-square analysis was performed on categorical variables.

\section{Results}

The baseline demographics and characteristics are shown in Table 1 . Of the patients who underwent mechanical thrombectomy, 3,230 were obese and 8,256 were non-obese. 


\section{Cureus}

\begin{tabular}{|c|c|c|c|c|c|c|c|}
\hline Demographics, ICD 10 codes/Diagnoses & Mean \pm SD & Min & Max & P-Value & Std diff & Patients & $\%$ of Cohort \\
\hline \multirow{2}{*}{ Age at index } & $67.2 \pm 13.4$ & 13 & 90 & \multirow{2}{*}{$<0.0001$} & \multirow{2}{*}{0.2372} & 3,230 & $100 \%$ \\
\hline & $70.5 \pm 14.6$ & 0 & 90 & & & 8,256 & $100 \%$ \\
\hline \multirow{3}{*}{ Female } & & & & \multirow{2}{*}{$<0.0001$} & \multirow{2}{*}{0.105} & 1,804 & $56 \%$ \\
\hline & & & & & & 4,179 & $51 \%$ \\
\hline & & & & \multirow{2}{*}{$<0.0001$} & \multirow{2}{*}{0.105} & 1,426 & $44 \%$ \\
\hline \multirow[t]{2}{*}{ Male } & & & & & & 4,077 & $49 \%$ \\
\hline & & & & \multirow{2}{*}{$<0.0001$} & \multirow{2}{*}{0.1512} & 2,382 & $74 \%$ \\
\hline \multirow{2}{*}{ Unknown race } & & & & & & 6,613 & $80 \%$ \\
\hline & & & & \multirow{2}{*}{$<0.0001$} & \multirow{2}{*}{0.0902} & 652 & $20 \%$ \\
\hline \multirow[t]{2}{*}{ White } & & & & & & 1,378 & $17 \%$ \\
\hline & & & & \multirow{2}{*}{$<0.0001$} & \multirow{2}{*}{0.1456} & 189 & $6 \%$ \\
\hline \multirow[t]{2}{*}{ African American } & & & & & & 238 & $3 \%$ \\
\hline & & & & \multirow{2}{*}{0.8821} & \multirow{2}{*}{0.0031} & 10 & $0 \%$ \\
\hline Asian & & & & & & 27 & $0 \%$ \\
\hline E08-E13 & & & & \multirow{2}{*}{$<0.0001$} & \multirow{2}{*}{0.4556} & 1,602 & $50 \%$ \\
\hline Diabetes mellitus & & & & & & 2,308 & $28 \%$ \\
\hline E78 & & & & \multirow{2}{*}{$<0.0001$} & \multirow{2}{*}{0.4244} & 2,398 & $74 \%$ \\
\hline Disorders of lipoprotein metabolism and other lipidemias & & & & & & 4,487 & $54 \%$ \\
\hline \multirow[b]{2}{*}{ Hypertensive diseases } & & & & & & 2,749 & $85 \%$ \\
\hline & & & & $<.0001$ & 0.4455 & 5,489 & $66 \%$ \\
\hline |20-|25 & & & & & & 1,424 & $44 \%$ \\
\hline Ischemic heart diseases & & & & $<0.0001$ & 0.2162 & 2,775 & $34 \%$ \\
\hline 173 & & & & & & 573 & $18 \%$ \\
\hline Other peripheral vascular diseases & & & & 0.0001 & 0.1762 & 947 & $11 \%$ \\
\hline J40-J47 & & & & & & 1,250 & $39 \%$ \\
\hline Chronic lower respiratory diseases & & & & $<0.0001$ & 0.2939 & 2,076 & $25 \%$ \\
\hline F17 & & & & & & 704 & $22 \%$ \\
\hline Nicotine dependence & & & & $<0.0001$ & $0.14 / 8$ & 1,323 & $16 \%$ \\
\hline $\mathrm{F} 10.1$ & & & & & & 126 & $4 \%$ \\
\hline Alcohol abuse & & & & 0.0500 & .0000 & 270 & $3 \%$ \\
\hline N17-N19 & & & & & & 1,143 & $35 \%$ \\
\hline Acute kidney failure and chronic kidney disease & & & & $<0.0001$ & 0.2712 & 1,912 & $23 \%$ \\
\hline K74 & & & & & & 73 & $2 \%$ \\
\hline Fibrosis and cirrhosis of liver & & & & & .0000 & 97 & $1 \%$ \\
\hline 148 & & & & & & 1,188 & $37 \%$ \\
\hline Atrial fibrillation and flutter & & & & $<0.0001$ & 0.1062 & 2,621 & $32 \%$ \\
\hline 150 & & & & & & 1,127 & $35 \%$ \\
\hline Heart failure & & & & $<0.0001$ & 0.2549 & 1,932 & $23 \%$ \\
\hline
\end{tabular}




\section{Cureus}

TABLE 1: Baseline demographics and characteristics. Top box represents cohort 1: thrombectomy and obese. Bottom box represents cohort 2: thrombectomy and non-obese.

ICD, International Classification of Diseases, Tenth Revision; Index, date of thrombectomy; Max, maximum; Min, minimum; SD, standard deviation; Std diff, standard difference

Figure 1 shows measures of association for cohort 1 (thrombectomy and obese) versus cohort 2

(thrombectomy and non-obese) for the outcome of mortality. Figure 2 shows a Kaplan-Meier analysis for this outcome. A total of $13.56 \%$ of patients in cohort 1 and $16.315 \%$ of patients in cohort 2 died $(p<0.0002$, odds ratio $[\mathrm{OR}]=0.805,95 \%$ confidence interval $[\mathrm{CI}]=0.716,0.904)$. Survival probability at the end of 1,600 days after mechanical thrombectomy was $72.223 \%$ for cohort 1 and $61.712 \%$ for cohort 2 .

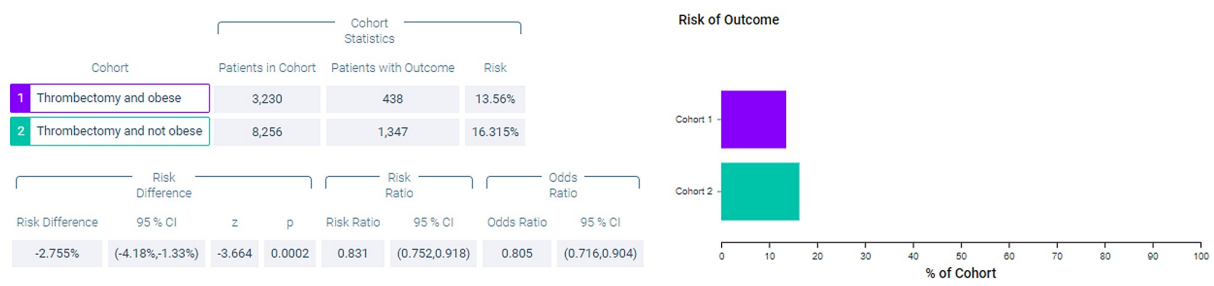

FIGURE 1: Measures of association for the outcome deceased.

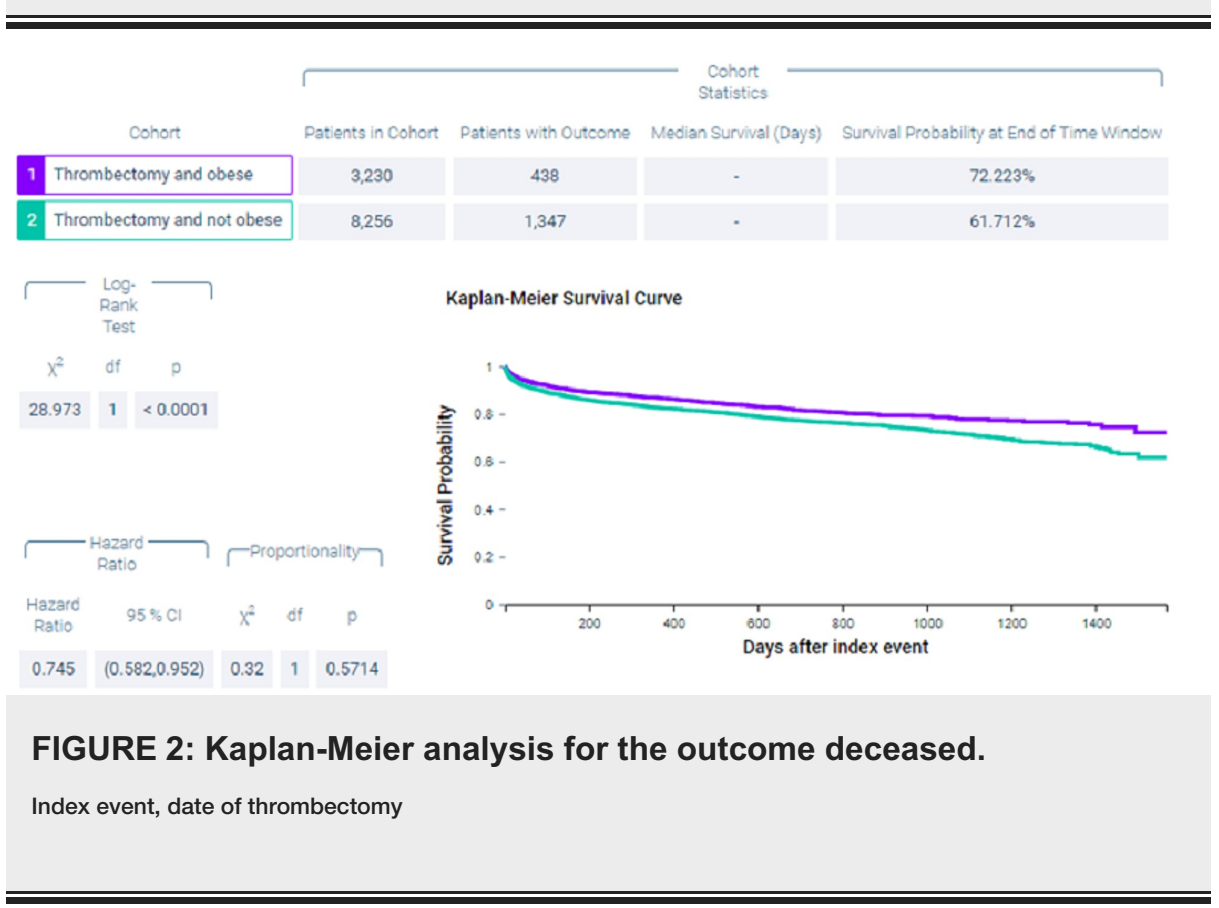

Because of the differences in baseline demographics seen in Table 1, cohorts were propensity score-matched (Figure 3). As seen in Table 2, after propensity score matching, both cohort 1 (thrombectomy and obese) and cohort 2 (thrombectomy and non-obese) included 3,020 patients.

\begin{tabular}{|c|c|c|c|c|c|c|c|}
\hline Demographics, ICD 10 codes/Diagnoses & Mean \pm SD & Min & Max & P-Value & Std diff & Patients & $\%$ of Cohort \\
\hline \multirow{2}{*}{ Age at index } & $67.9 \pm 13.1$ & & & $0.8 / 06$ & 0.0042 & 3,020 & $100 \%$ \\
\hline & $67.9 \pm 15.3$ & & & & & 3,020 & $100 \%$ \\
\hline \multirow{3}{*}{ Female } & & & & 0.9056 & 0.0031 & 2,258 & $74.77 \%$ \\
\hline & & & & & & 2,262 & $74.90 \%$ \\
\hline & & & & 0.7959 & 0.0068 & 1,656 & $54.83 \%$ \\
\hline Male & & & & & & 1,666 & $55.17 \%$ \\
\hline
\end{tabular}




\section{Cureus}

\begin{tabular}{|c|c|c|c|c|}
\hline & 0.7959 & 0.0067 & 1,364 & $45.17 \%$ \\
\hline \multirow[t]{2}{*}{ Unknown race } & & & 1,354 & $44.83 \%$ \\
\hline & 0.6753 & 0.0108 & 608 & $20.13 \%$ \\
\hline \multirow[t]{2}{*}{ White } & & & 595 & $19.70 \%$ \\
\hline & 0.5562 & 0.0151 & 147 & $4.87 \%$ \\
\hline \multirow[t]{2}{*}{ African American } & & & 157 & $5.20 \%$ \\
\hline & 1 & $<0.0001$ & 10 & $0.33 \%$ \\
\hline Asian & & & 10 & $0.33 \%$ \\
\hline E08-E13 & 0.6002 & 0.0135 & 2,539 & $84.07 \%$ \\
\hline Diabetes mellitus & & & 2,524 & $83.58 \%$ \\
\hline E78 & 0.885 & 0.0037 & 2,198 & $72.78 \%$ \\
\hline Disorders of lipoprotein metabolism and other lipidemias & & & 2,203 & $72.95 \%$ \\
\hline |10-|16 & 0.8165 & 0.006 & 1,411 & $46.72 \%$ \\
\hline Hypertensive diseases & & & 1,420 & $47.02 \%$ \\
\hline |20-125 & 0.3353 & 0.0248 & 1,298 & $42.98 \%$ \\
\hline Ischemic heart diseases & & & 1,261 & $41.76 \%$ \\
\hline 173 & 0.7687 & 0.0076 & 1,106 & $36.62 \%$ \\
\hline Other peripheral vascular diseases & & & 1,095 & $36.26 \%$ \\
\hline J40-J47 & 0.6878 & 0.0103 & 1,098 & $36.36 \%$ \\
\hline Chronic lower respiratory diseases & & & 1,083 & $35.86 \%$ \\
\hline F17 & 0.228 & 0.031 & 1,014 & $33.58 \%$ \\
\hline Nicotine dependence & & & 970 & $32.12 \%$ \\
\hline F10.1 & 0.7634 & 0.0077 & 1,002 & $33.18 \%$ \\
\hline Alcohol abuse & & & 991 & $32.82 \%$ \\
\hline N17-N19 & 0.7741 & 0.0074 & 623 & $20.63 \%$ \\
\hline Acute kidney failure and chronic kidney disease & & & 614 & $20.33 \%$ \\
\hline K74 & 0.6279 & 0.0125 & 507 & $16.79 \%$ \\
\hline Fibrosis and cirrhosis of liver & & & 493 & $16.33 \%$ \\
\hline 148 & 0.2357 & 0.0305 & 115 & $3.81 \%$ \\
\hline Atrial fibrillation and flutter & & & 98 & $3.25 \%$ \\
\hline 150 & 0.846 & 0.005 & 53 & $1.76 \%$ \\
\hline Heart failure & & & 55 & $1.82 \%$ \\
\hline
\end{tabular}

TABLE 2: Baseline demographics and characteristics after matching. Top box represents cohort 1: thrombectomy and obese. Bottom box represents cohort 2: thrombectomy and non-obese.

ICD, International Classification of Diseases, Tenth Revision; Index, date of thrombectomy; Max, maximum; Min, minimum; SD, standard deviation; Std diff, standard difference 


\section{Cureus}

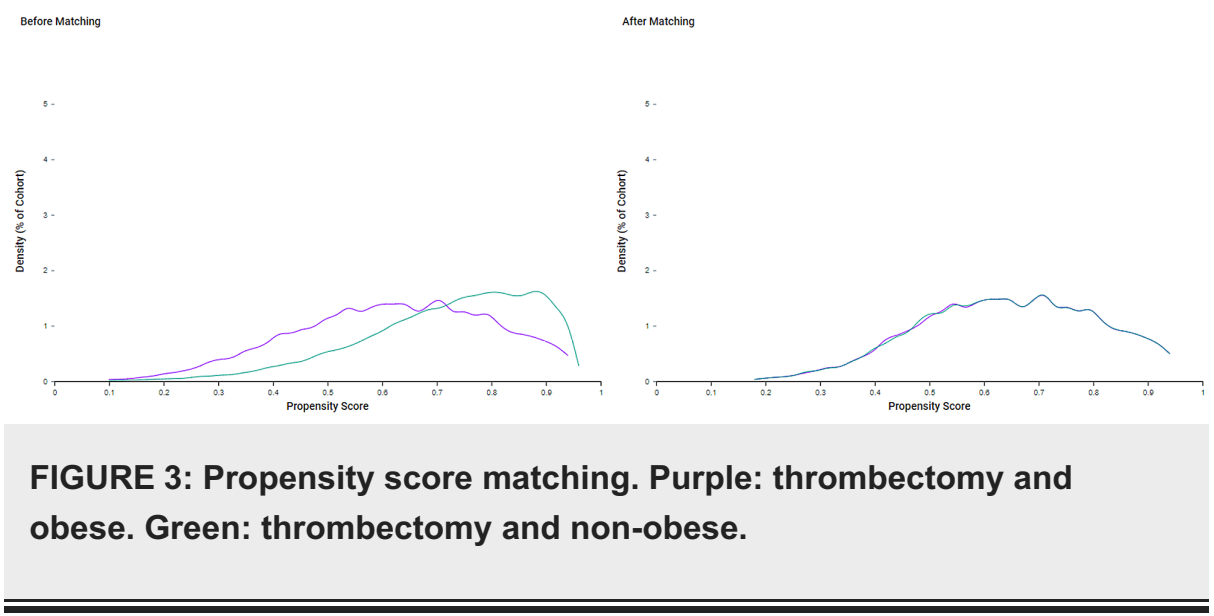

Figure 4 shows measures of association for both cohort 1 (thrombectomy and obese) and cohort 2 (thrombectomy and non-obese) for the outcome of mortality. Figure 5 shows a Kaplan-Meier analysis for this outcome. A total of $13.874 \%$ of patients in cohort 1 and $16.589 \%$ of patients in cohort 2 died $(p=0.0033$, $\mathrm{OR}=0.81,95 \% \mathrm{CI}=0.704,0.932)$. Survival probability at the end of 1,600 days after mechanical thrombectomy was $71.566 \%$ for cohort 1 and $63.792 \%$ for cohort 2 .
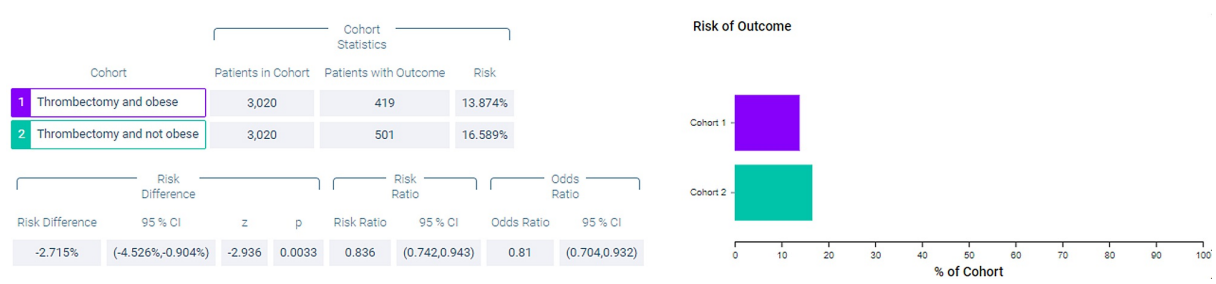

FIGURE 4: Measures of association for the matched cohort; outcome: deceased.

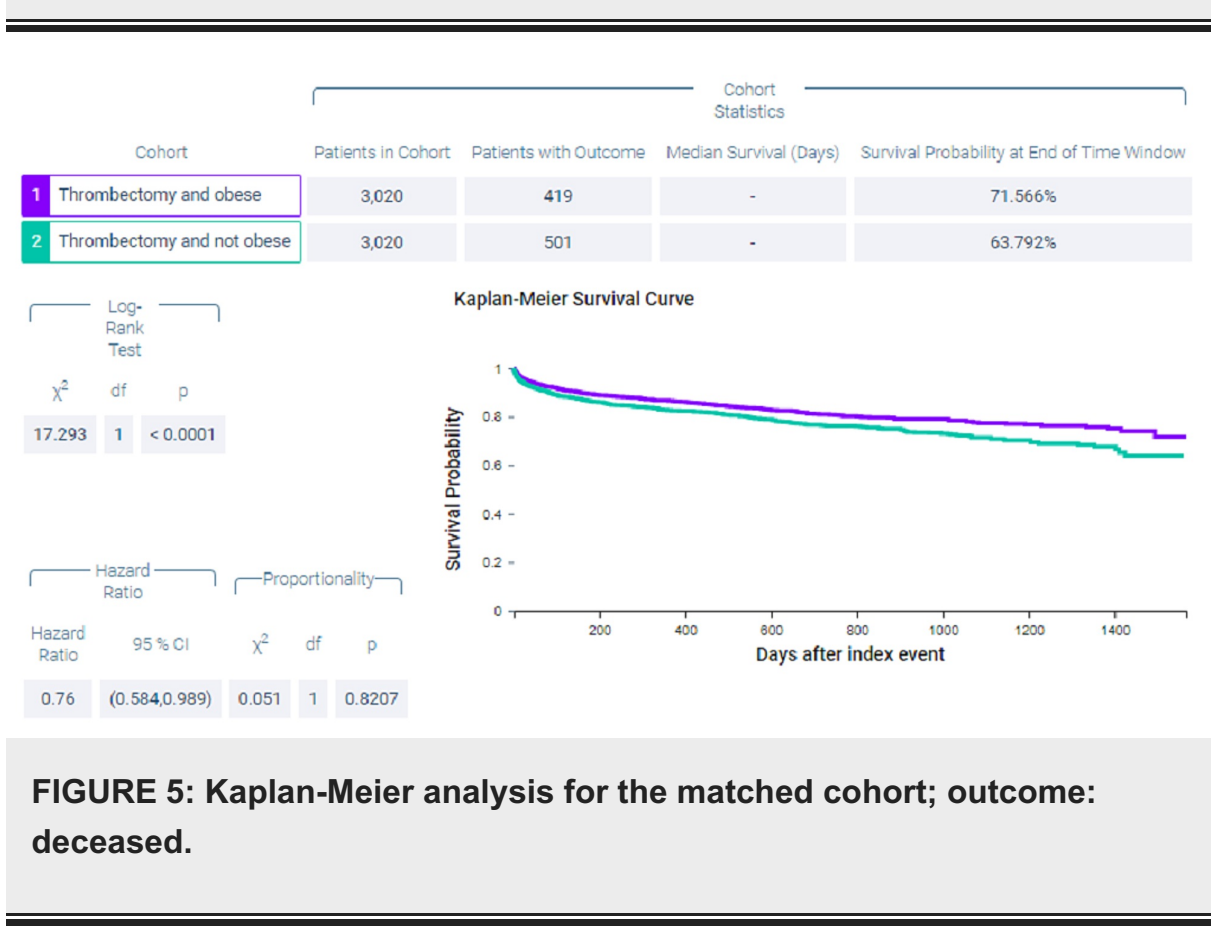

Figure 6 shows measures of association for both cohort 1 (thrombectomy and obese) and cohort 2 (thrombectomy and non-obese) for the outcome of ventilator dependence. Figure 7 shows a Kaplan-Meier analysis for this outcome. A total of $7.947 \%$ of patients in cohort 1 required ventilator use compared to $7.351 \%$ of patients in cohort $2(\mathrm{p}=0.3835, \mathrm{OR}=1.088,95 \% \mathrm{CI}=0.9,1.316)$. 


\section{Cureus}

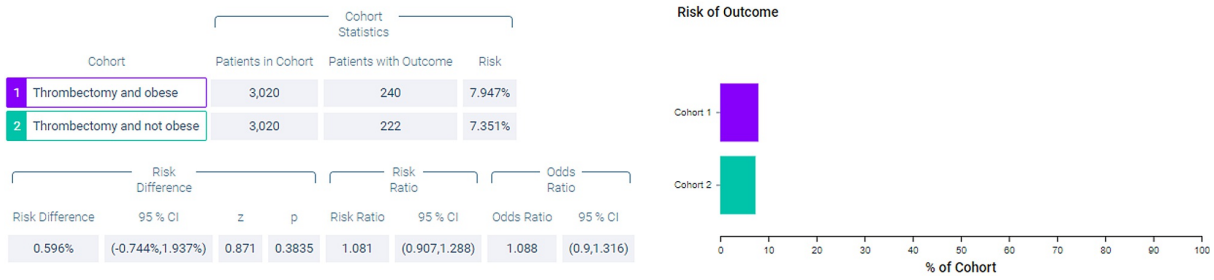

FIGURE 6: Measures of association for the matched cohort; outcome: ventilator dependence.

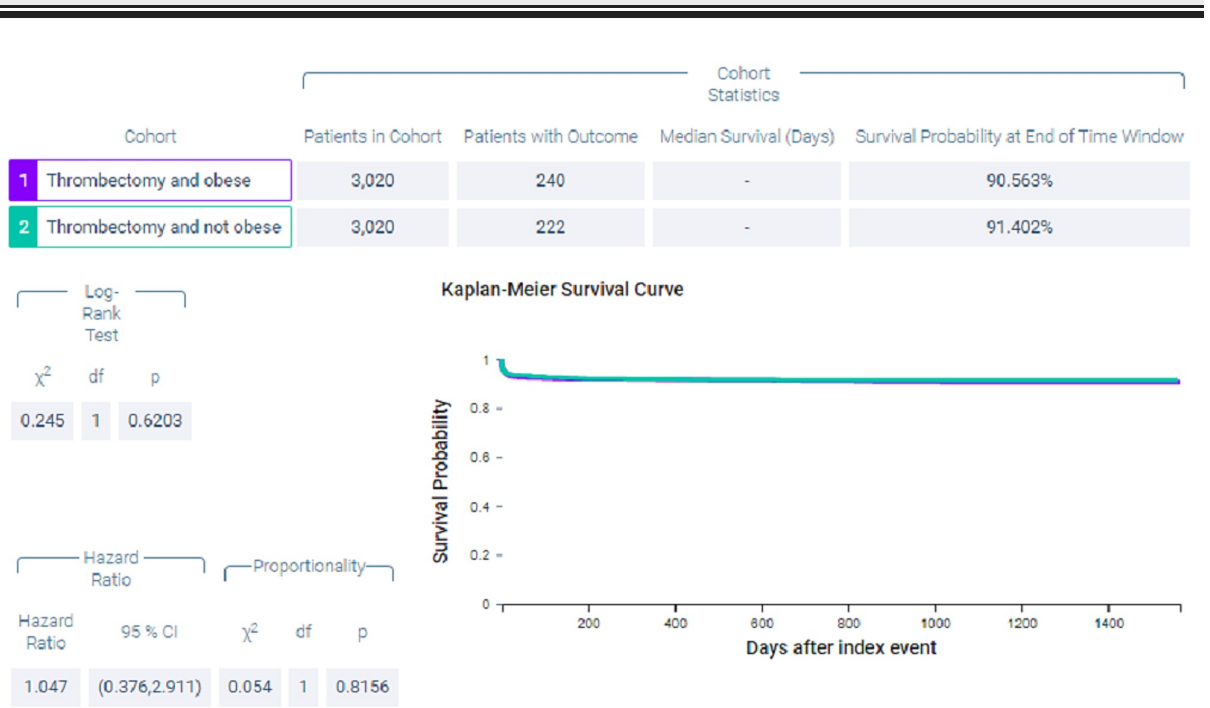

FIGURE 7: Kaplan-Meier analysis for the matched cohort; outcome: ventilator dependence.

Figure 8 shows measures of association for both cohort 1 (thrombectomy and obese) and cohort 2 (thrombectomy and non-obese) for the outcome of hemicraniectomy. Figure 9 shows a Kaplan-Meier analysis for this outcome. A total of $2.152 \%$ of patients in cohort 1 underwent hemicraniectomy compared to $1.49 \%$ of patients in cohort $2(\mathrm{p}=0.0543, \mathrm{OR}=1.454,95 \% \mathrm{CI}=0.991,2.134)$.
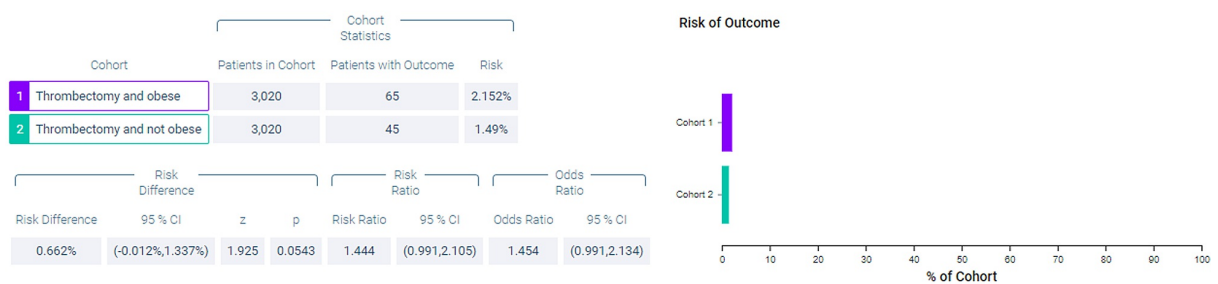

FIGURE 8: Measures of association for the matched cohort; outcome: hemicraniectomy. 


\section{Cureus}

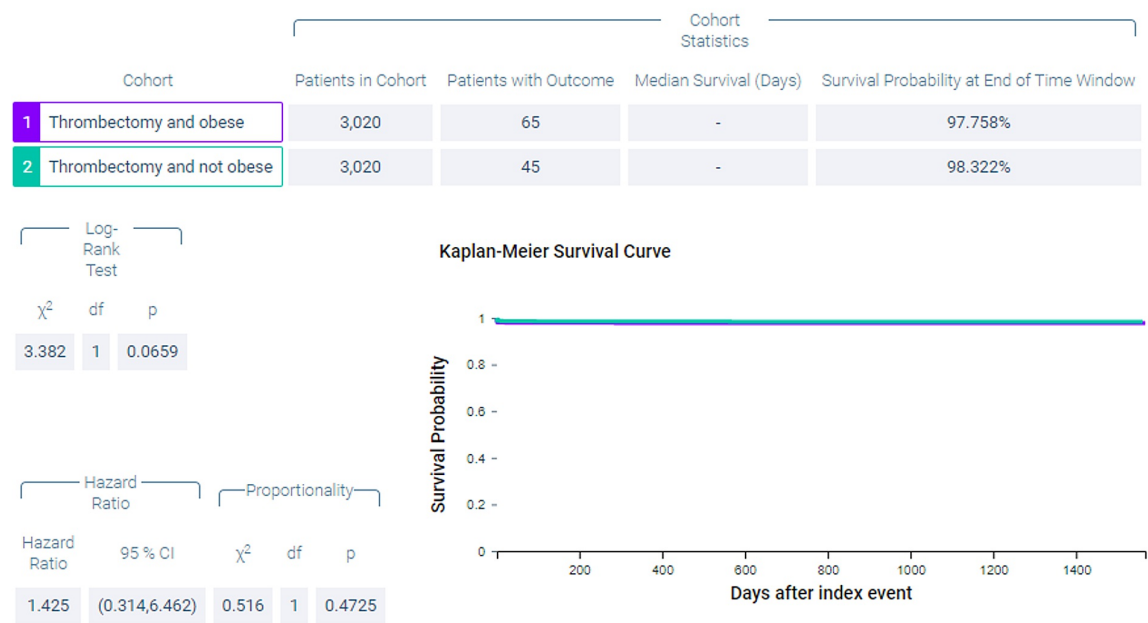

FIGURE 9: Kaplan-Meier analysis for the matched cohort; outcome: hemicraniectomy.

Figure 10 shows measures of association for both cohort 1 (thrombectomy and obese) and cohort 2 (thrombectomy and non-obese) for the outcome of intracerebral hemorrhage. Figure 11 shows a KaplanMeier analysis for this outcome. A total of $18.609 \%$ of patients in cohort 1 experienced post-procedural intracerebral hemorrhage compared to $18.377 \%$ of patients in cohort 2 ( $p=0.8165, \mathrm{OR}=1.015,95 \% \mathrm{CI}=$ $0.892,1.156)$.

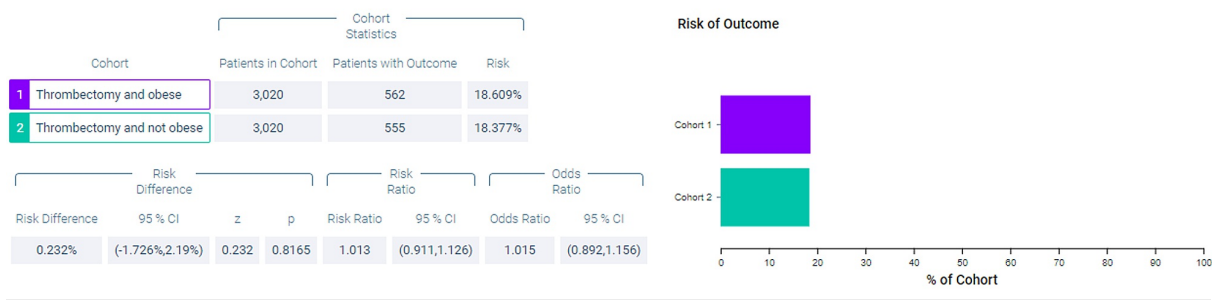

FIGURE 10: Measures of association for the matched cohort; outcome: intracerebral hemorrhage.

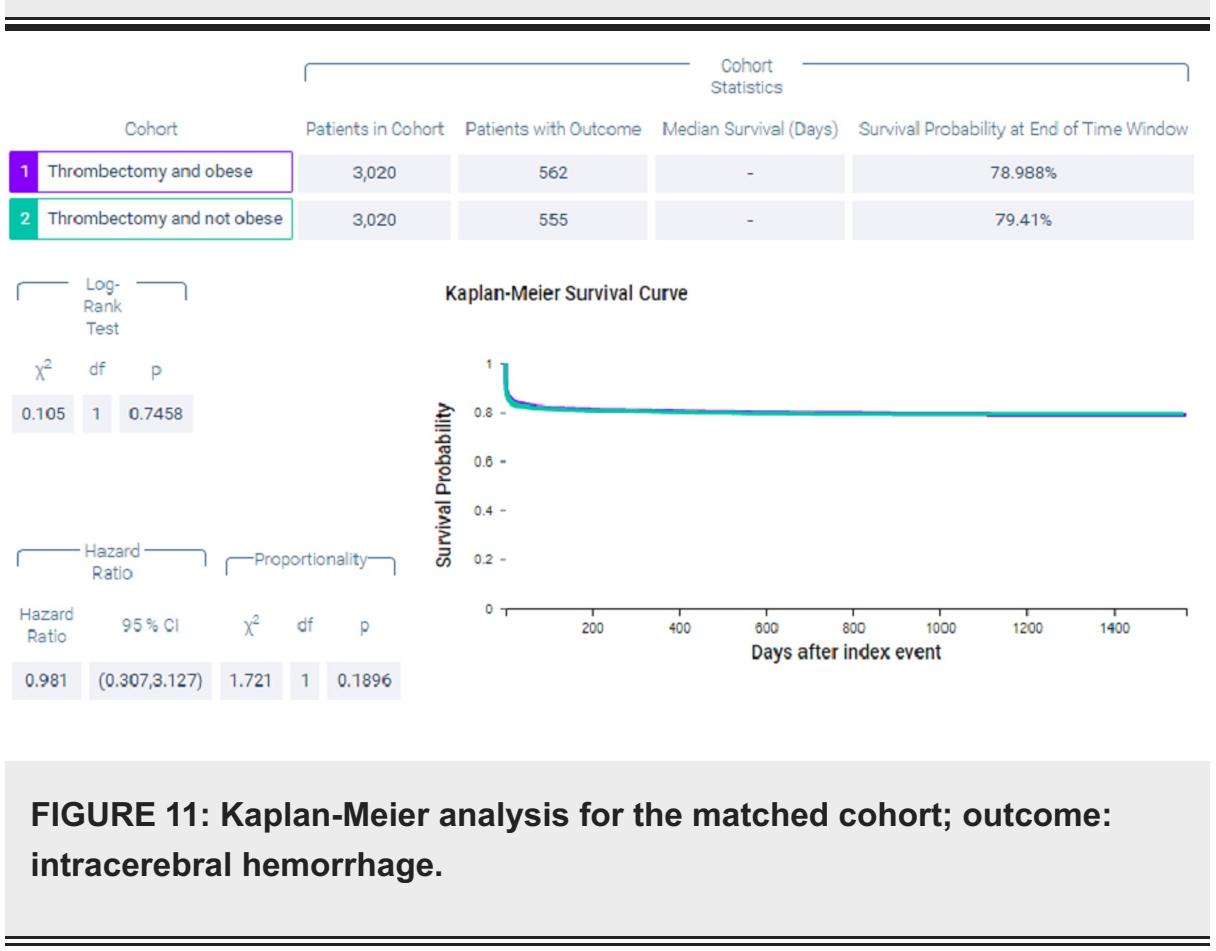




\section{Discussion}

Over $30 \%$ of the world's population is estimated to be overweight, and this number is increasing [4]. A metaanalysis from 2008 showed that patients with higher BMI had better mortality in heart failure. Further studies have shown similar outcomes in patients undergoing percutaneous coronary intervention, dialysis, those with rheumatoid arthritis, chronic obstructive pulmonary disease, and various wasting diseases [4,1722]. This became known as the obesity paradox, wherein those undergoing vascular reperfusion for myocardial infarction and obese patients had decreased mortality [3,23,24].

Of the 12 studies examining BMI and stroke, 10 showed higher BMI to be associated with lower mortality [414]. Two of the studies did not show such an association when adjusted for stroke severity [16] and when looking at mortality within a 30-day period [15]. To my knowledge, only one study examined BMI as it relates to mechanical thrombectomy. It is possible that higher BMI might influence time to arterial puncture due to increased difficulties gaining arterial access in obese patients, transporting obese patients, and transferring obese patients [3]. They found that higher BMI is associated with decreased intracerebral hemorrhage post-procedure, and that BMI correlates with higher non-hemorrhagic inpatient mortality [3]. However, the results of this study disagree and show no statistical difference in post-procedure hemorrhage rates, as well as decreased mortality in obese patients.

This analysis was not without limitations. The major limitation of this study was that it was retrospective in nature. Furthermore, due to the nature of the database, patient-level data on specific outcomes could not be collected. Moreover, radiology information was not available. Additionally, information on the type of diagnostic test used for the confirmation of disease was not available. The data collected was for billing purposes, not for clinical use, and thus much clinical information is missing. In addition, some misidentification is inevitable in database studies.

\section{Conclusions}

Despite increasing risk of ischemic stroke, obese patients who undergo mechanical thrombectomy have decreased mortality rates compared to their non-obese counterparts. Future studies can use a frailty index to assess mortality in this population.

\section{Additional Information \\ Disclosures}

Human subjects: Consent was obtained or waived by all participants in this study. Animal subjects: All authors have confirmed that this study did not involve animal subjects or tissue. Conflicts of interest: In compliance with the ICMJE uniform disclosure form, all authors declare the following: Payment/services info: All authors have declared that no financial support was received from any organization for the submitted work. Financial relationships: All authors have declared that they have no financial relationships at present or within the previous three years with any organizations that might have an interest in the submitted work. Other relationships: All authors have declared that there are no other relationships or activities that could appear to have influenced the submitted work.

\section{References}

1. Strazzullo P, D’Elia L, Cairella G, Garbagnati F, Cappuccio FP, Scalfi L: Excess body weight and incidence of stroke: meta-analysis of prospective studies with 2 million participants. Stroke. 2010, 41:26. 10.1161/STROKEAHA.109.576967

2. Kurth T, Gaziano JM, Berger K, et al.: Body mass index and the risk of stroke in men . Arch Intern Med. 2002, 162:2557-62. 10.1001/archinte.162.22.2557

3. Chen SH, McCarthy D, Saini V, Brunet MC, Peterson EC, Yavagal D, Starke RM: Effect of body mass index on outcomes of mechanical thrombectomy in acute ischemic stroke. World Neurosurg. 2020, 143:503-15. 10.1016/j.wneu.2020.07.220

4. Oesch L, Tatlisumak T, Arnold M, Sarikaya H: Obesity paradox in stroke \pm myth or reality? A systematic review. PLoS One. 2017, 12:0171334. 10.1371/journal.pone.0171334

5. Olsen TS, Dehlendorff C, Petersen HG, Andersen KK: Body mass index and poststroke mortality. Neuroepidemiology. 2008, 30:93-100. 10.1159/000118945

6. Andersen KK, Olsen TS: The obesity paradox in stroke: lower mortality and lower risk of readmission for recurrent stroke in obese stroke patients. Int J Stroke. 2015, 10:99-104. 10.1111/ijs.12016

7. Towfighi A, Ovbiagele B: The impact of body mass index on mortality after stroke . Stroke. 2009, 40:2704-8. 10.1161/STROKEAHA.109.550228

8. Vemmos K, Ntaios G, Spengos K, et al.: Association between obesity and mortality after acute first-ever stroke: the obesity-stroke paradox. Stroke. 2011, 42:30-6. 10.1161/STROKEAHA.110.593434

9. Kim BJ, Lee SH, Ryu WS, Kim CK, Lee J, Yoon BW: Paradoxical longevity in obese patients with intracerebral hemorrhage. Neurology. 2011, 76:567-73. 10.1212/WNL.0b013e31820b7667

10. Kim BJ, Lee SH, Jung KH, Yu KH, Lee BC, Roh JK, For Korean Stroke Registry investigators: Dynamics of obesity paradox after stroke, related to time from onset, age, and causes of death. Neurology. 2012, 79:85663. 10.1212/WNL.0b013e318266fad1

11. Bell CL, Lacroix A, Masaki K, et al.: Prestroke factors associated with poststroke mortality and recovery in 
older women in the women's health initiative. J Am Geriatr Soc. 2013, 61:1324-30. 10.1111/jgs.12361

12. Skolarus LE, Sanchez BN, Levine DA, et al.: Association of body mass index and mortality after acute ischemic stroke. Circ Cardiovasc Qual Outcomes. 2014, 7:64-9. 10.1161/CIRCOUTCOMES.113.000129

13. Zhao L, Du W, Zhao X, et al.: Favorable functional recovery in overweight ischemic stroke survivors: findings from the China National Stroke Registry. J Stroke Cerebrovasc Dis. 2014, 23:201-6.

10.1016/j.jstrokecerebrovasdis.2013.10.002

14. Doehner W, Schenkel J, Anker SD, Springer J, Audebert H: Overweight and obesity are associated with improved survival, functional outcome, and stroke recurrence after acute stroke or transient ischaemic attack: observations from the TEMPiS trial. Eur Heart J. 2013, 34:268-77. 10.1093/eurheartj/ehs340

15. Dehlendorff C, Andersen KK, Olsen TS: Body mass index and death by stroke no obesity paradox . JAMA Neurol. 2014, 71:978-84. 10.1001/jamaneurol.2014.1017

16. Ryu WS, Lee SH, Kim CK, Kim BJ, Yoon BW: Body mass index, initial neurological severity and long-term mortality in ischemic stroke. Cerebrovasc Dis. 2011, 32:170-6. 10.1159/000328250

17. Oreopoulos A, Padwal R, Kalantar-Zadeh K, Fonarow GC, Norris CM, McAlister FA: Body mass index and mortality in heart failure: a meta-analysis. Am Heart J. 2008, 156:13-22. 10.1016/j.ahj.2008.02.014

18. Hastie CE, Padmanabhan S, Slack R, et al.: Obesity paradox in a cohort of 4880 consecutive patients undergoing percutaneous coronary intervention. Eur Heart J. 2010, 31:222-6. 10.1093/eurheartj/ehp317

19. Kalantar-Zadeh K, Block G, Humphreys MH, Kopple JD: Reverse epidemiology of cardiovascular risk factors in maintenance dialysis patients. Kidney Int. 2003, 63:793-808. 10.1046/j.1523-1755.2003.00803.x

20. Escalante A, Haas RW, Del Rincón I: Paradoxical effect of body mass index on survival in rheumatoid arthritis: role of comorbidity and systemic inflammation. Arch Intern Med. 2005, 165:1624-9. 10.1001/archinte.165.14.1624

21. Landbo C, Prescott E, Lange P, Vestbo J, Almdal TP: Prognostic value of nutritional status in chronic obstructive pulmonary disease. Am J Respir Crit Care Med. 1999, 160:1856-61.

10.1164/ajrccm.160.6.9902115

22. Kalantar-Zadeh K, Horwich TB, Oreopoulos A, Kovesdy CP, Younessi H, Anker SD, Morley JE: Risk factor paradox in wasting diseases. Curr Opin Clin Nutr Metab Care. 2007, 10:433-42. 10.1097/MCO.0b013e3281a30594

23. Romero-Corral A, Montori VM, Somers VK, et al.: Association of bodyweight with total mortality and with cardiovascular events in coronary artery disease: a systematic review of cohort studies. Lancet. 2006, 368:666-78. 10.1016/S0140-6736(06)69251-9

24. Yusuf PS, Hawken S, Ônpuu S, et al.: Effect of potentially modifiable risk factors associated with myocardial infarction in 52 countries (the INTERHEART study): case-control study. Lancet. 2004, 364:93752. 10.1016/S0140-6736(04)17018-9 